\title{
An analysis of ophthalmology trainees' perceptions of feedback for cataract surgery training
}

This article was published in the following Dove Press journal:

Clinical Ophthalmology

II December 2013

Number of times this article has been viewed

\section{Habiba Saedon \\ Birmingham Midland Eye Centre, Birmingham, West Midlands, UK}

Correspondence: Habiba Saedon Birmingham Midland Eye Centre, Dudley Rd, Birmingham, West Midlands BI8 7QH, UK Email h.saedon@nhs.net
Objectives: To determine whether feedback for cataract surgery is perceived to be given to trainee ophthalmologists, the way in which any feedback is given, and what the trainee perceives to be the effect of feedback on their performance.

Design: Cross-sectional qualitative study.

Participants: Twelve trainee ophthalmologists at various levels of specialty training in the UK.

Methods: Semi-structured interviews were conducted via telephone or face to face. Interviews were transcribed and underwent thematic analysis using a qualitative software data package.

Main outcome measures: The importance of feedback to the trainee and methods to improve the giving of feedback.

Results: Feedback was thought to be a useful tool for improving performance in cataract surgery by all participants. Emergent themes were the importance of specificity of feedback and having confidence in the supervisor. Participants suggested ways that the feedback given can be improved upon. An insight was gained into how the feedback has an effect on their performance.

Conclusion: This study showed that trainees perceive the feedback they receive to be of high quality. Feedback enables the trainees to self-reflect and improve their surgical techniques.

Keywords: postgraduate training, education, phacoemulsification, microsurgical skills, cognitive learning, reflection

\section{Introduction}

Doctors training in Ophthalmology commence cataract surgery training from the start of their specialty training in most parts of the UK. The Royal College of Ophthalmologists, which is responsible for setting standards for the practice of ophthalmology in the UK, suggests that 350 cases of cataract surgery should be performed by every trainee as the primary surgeon by the end of training. ${ }^{1}$

There is no standardized method for the teaching or learning of cataract surgery. There is little in the literature describing cataract surgery from the learners' point of view. Current evidence focuses on the most effective ways to teach the procedure. There is also extensive information on the assessment of learners for cataract surgery. The aims of this study were to determine whether the feedback given during cataract surgery training is structured, whether it is formalized through documentation, and whether the participant considers it to be beneficial to their subsequent performance.

\section{Theoretical framework}

Feedback has become an integral part of learning within the medical profession, particularly as training becomes more learner-centered. Effective feedback may be 
defined as feedback in which information about previous performance is used to promote positive and desirable development. ${ }^{2}$ Shorter working hours and reduced length of training means every learning opportunity needs to be seized upon and maximized. The general principles of adult learning suggest that adult learners welcome feedback, especially when it is based on their performance and tailored to their goals. ${ }^{3}$ The primary goal of giving feedback is to encourage reflection by the learners on their actions leading to a subsequent improvement in performance.

\section{Materials and methods}

The study employed an interactionist approach whereby interviews were used for qualitative data collection and analysis. ${ }^{4}$ The study was prospective across a number of Deaneries across the UK. Participants were recruited via email invitation and respondents contacted. Data collection began in February 2011 and was completed in April 2011. Interviews were conducted by telephone and face to face. Using the telephone as a mechanism for data collection in health research has increased in recent years and has been shown to be an effective way of collecting data. ${ }^{5-7}$ All interviews were tape-recorded with permission from participants, then transcribed onto an $\operatorname{Excel}^{\circledR}$ (Microsoft Corporation, Redmond, WA, USA) file and then imported into the qualitative data analysis software package NVivo9 (QSR International Pty Ltd, Doncaster, VIC, Australia) version 9. Data were subjected to a process of thematic coding and mapping to identify categories. Data codes were then mapped electronically to streamline the themes and to map their relationships. Specifically, coded comments were extracted by theme, using "tree nodes" in NVivo, to provide an overview across the whole sample. All data collection procedures were approved by the relevant institutional research ethics board prior to initiation, and all participants provided informed, written consent to participate.

\section{Results}

\section{General findings}

Twelve trainees were interviewed over a period of 3 months from February 2011 to April 2011. Their experience ranged from 10 months to more than 10 years of ophthalmology training (mean average 4.1 years), with their years of training ranging from Specialty Trainee (ST) Year 1 (one participant), ST2 (three participants), ST3 (four participants), ST4 (two participants), ST6 (one participant), and ST7 (one participant). Specialty training in ophthalmology is from years 1 to 7, and therefore a good range of trainee experiences were recruited. Four were female, and 8 were male. The participants were recruited from Deaneries across England, including North Western (three trainees), West Midlands (six trainees), East Midlands (one trainee), Yorkshire (one trainee), and London (one trainee).

The number of cataract cases previously performed by the trainees ranged from 12 by the most junior trainee to over 1,000 by the most experienced trainee, the mean average being 308 (median 300). The number of cases the trainee performed on the list range from one by the most junior trainee and some ST2 s to six out of seven cases (an ST4 trainee). One ST3 trainee also performed one cataract case on the list out of seven.

The trainer was scrubbed only with the ST1 trainee. Only the most senior trainees (ST6 and 7) were performing unsupervised lists. These trainees were not unsupervised for every list, only occasional lists, and received feedback when they were supervised. Even the most senior trainees found that the supervisor scrubbed with them if they began working in a new hospital. All trainees were supervised by a consultant, except for one at the ST3 training level. This trainee was supervised by a senior registrar who had not had any formal training in teaching cataract surgery.

All trainees except one perceived receiving any feedback at all for their cataract surgery. Five of the 12 trainees asked for the feedback. The trainee who did not perceive receiving feedback did not ask for feedback. This indicates that a high percentage of trainees receive feedback, and it is mostly given without asking for it, but if it is not asked for, it may not be received. Six trainees receive feedback for each case they performed, another for every case the trainer watched, another for at least one case on the list. This trainee recorded the case and viewed it afterwards with the trainer, even if the trainer had been watching. Others did not usually receive feedback for each case they performed, but only did if it was a complicated case, or if the trainee found the case difficult, they would seek feedback from the trainer.

All trainees received verbal feedback. In addition, three trainees also received diagram-assisted feedback. In terms of timing of the feedback, most received it either at the end of the case (eight trainees) or the end of the list (two trainees). Another said at the end of the case if they had struggled, otherwise at the end of the list. Finally, another trainee would receive feedback at the end of the list typically, but if they had a complication, they would be talked through it, thereby receiving feedback during the case.

All trainees found the feedback they received useful. It was thought to be useful in improving technique and 
making the trainee reflect more effectively at how they were performing. One trainee said that sometimes they did not notice things that other people picked up on and felt that the trainer was in a better position to point these things out because of their greater experience.

\section{Improving the feedback}

Some trainees complained that they would like to receive more feedback. As one trainee said:

Not all consultants do it. It's hit and miss but I've been lucky with my jobs in that at least one consultant I'm with will give feedback but maybe it should be every list you're in they should give you at least a session at the end, whether weekly or two-weekly.

Another senior trainee said:

Apart from going through recordings, it needs to be a conscious thing in the trainer and trainee's mind that there is a balance between just getting on with things. I think the idea that a proportion of your work, depending on your stage of training, is scrutinized is a really good thing so the consultant will watch one of your cases as a senior trainee to comment on anything they observe. The trainer and trainee should be expectant that feedback will need to be given, to a greater or lesser extent. At the moment, there is an expectation that if the registrar can get on with the list then the consultant can get on with the admin work for the whole list. That's okay sometimes but not all the time because the trainee may develop bad habits or may lose confidence or run into problems.

A recurrent theme for how the feedback given could be improved was specificity. One trainee mentioned an example whereby they were operating on a hypermature cataract, and one specific part of the operation was beginning to go wrong in that the capsulorhexis was going out of position. The consultant asked whether they were happy to continue and they then converted to a different type of cataract extraction, extracapsular rather than phacoemulsification. They then had a discussion about specific points at the end of the case.

Others said they would like feedback to be more structured, by systematically going through each stage of the operation for example. Videoing and watching it back with the trainer was thought to be a useful technique by two trainees. Also, one felt the use of diagrams should be increased in order to aid visualization of surgical techniques. It was believed that this could improve understanding of things which could not necessarily be found in a textbook. One trainee felt that they would benefit from their trainer watching them do some straightforward cases and give some tips that would be helpful to improve their technique. Time was also an issue, as one trainee pointed out that a period should be set aside at the end of a case to sit down and discuss the case in more detail.

\section{Effect of feedback on subsequent performance}

All trainees felt that the feedback had an effect on their subsequent performance of cataract surgery. For example, one trainee said:

When I've made an error and I don't know where I went wrong, then when you review it with the consultant and figure it out, you can take those steps a bit slower or manage them differently so it doesn't happen again.

Another said:

It means I feel much more confident in deciding what I should be doing if something were to go wrong in surgery. I might use my own common sense, read books or watch educational videos but ultimately I would have to navigate forward myself, using my own judgment, and I might be less confident in doing so. If someone senior and more experienced had watched me, and who says where they think I went wrong and what I should try next, then I can confidently navigate through that problem patch to find a better way of proceeding. I think it's more like when you get plateaus during cataract surgery when all of a sudden for some reason you have a major problem with your rhexis or the iris keeps prolapsing, and you have a mental block or have complications, it's very hard to get yourself through that mental block no matter how much reading or practicing you do. Whereas if you have someone senior advising you then you can hand over some of the responsibility to them and it helps you through that spell. For me, the main advantage is getting you through problem patches.

Another trainee thought that experience and getting used to different situations is more important than feedback. Yet another said it had reduced their complication rate and made them more confident in managing complications. This direct impact on patient care demonstrates the importance of feedback. One trainee summarized the effect on their performance when they said: "I will change the way I operate according to the suggestions they have made." 


\section{Discussion}

This study has generated an insight into trainee ophthalmologists' perceptions of feedback for cataract surgery. Learners generally want feedback. They recognize the usefulness of it as a tool for improving their surgical skills.

Obtaining feedback that was meaningful to the trainees is essential if the process is going to improve the quality of professional practice. Obtaining peer feedback that the practitioner wanted and needed and how feedback was different from a performance appraisal, which was an employer's responsibility has previously been described. ${ }^{8}$ Peer feedback enhanced the practitioner's insight into what they did well. It also identified opportunities to improve. They suggested that writing a contract with peers might assist in obtaining constructive and appropriate feedback.

The trainee ophthalmologists in this study felt the quality of the care they provided improved, accountability increased, and self-awareness was enhanced by the feedback they received. The trainees indicated that feedback helped to protect the health and welfare of patients. They identified the impact on relationships, inflation of evaluations, and the time involved in completing feedback as negative concerns. The participants described the process as improving confidence and trust, and increasing the trainees' sense of ownership for their practice. Although some positive outcomes had been recognized, feedback could also be viewed as unwelcome and that the fear of criticism was a strong restraining force to participation.

The continued integration of feedback education and practice into postgraduate training is therefore essential. This will assist in reducing fear and defensiveness for ophthalmologists of the future. It is essential that curricula include communication and "training the trainers" courses to help ophthalmologists become effective in giving and receiving feedback.

Contemporary cognitivism emphasizes mental processes and proposes that many aspects of learning may be unique to the human species. Cognitivism has affected educational theory by emphasizing the role of the teacher in terms of the instructor's effectiveness of presentation of instructional material in a manner that facilitates students' learning. This includes helping learners to review and connect previous learning on a topic before moving to new ideas about that topic and helping learners understand the material by organizing it effectively. ${ }^{9}$

The relationship between feedback and outcome is not always straightforward and may not always achieve the desired results. ${ }^{10}$ Good feedback can lead to increased motivation and confidence in trainees. On the other hand, negative feedback is not aimed to demotivate or demoralize a trainee, but should be taken as constructive criticism for trainees to improve.

The study has shown that the mechanism for feedback within the different sites where training was taking place was dependent on the supervising surgeon. The training program may benefit from a standardized cognitive, wet laboratory, and simulation training ${ }^{11}$ curriculum for teaching cataract surgery and a standardized approach to supervision and feedback.

\section{Limitations of the study}

The different methods of interviewing was a possible cause for variability, because one participant was interviewed face to face and the rest by telephone. There are some disadvantages to telephone interviews. Unlike in-person interviews, multiple methods of communication cannot be used during telephone communication. Changes in body language and other visual cues that may indicate confusion, irritability, and so on, are lost when undertaking telephone interviews. $^{5}$

A larger sample may have increased the power of the research, but a saturation of data had been reached after 12 interviews. $^{12}$

\section{Conclusion}

This qualitative study has shown that trainees perceive the feedback they receive to be of high quality. It enables them to self-reflect and improve their techniques. The trainees have suggested ways that it can be improved upon, and this will be crucial when they become trainers themselves. They will be responsible for providing the service in the future, and training the surgeons of the future. It is an endless cycle which will evolve as teaching methods and surgical practices evolve.

\section{Financial support}

This research was funded by a West Midlands Deanery Medical Education Bursary. The sponsor had no role in the design or conduct of this research.

\section{Disclosure}

No conflicting relationship exists for the author.

\section{References}

1. Royal College of Ophthalmologists. Revalidation. Available from: http:// www.rcophth.ac.uk/page.asp? section=700\&search=. Accessed June 1, 2012. 
2. Archer JC. State of the science in health professional education: effective feedback. Med Educ. 2010;44(1):101-108.

3. Knowles MS. The Modern Practice of Adult Education. San Francisco, CA: Jossey-Bass Publishers; 1980:14.

4. Crotty M. The Foundations of Social Research. London, UK: Sage Publications; 1998.

5. Carr ECJ, Worth A. The use of the telephone interview for research. Nurs Times Res. 2001;6(1):511-524.

6. Evans M, Kessler D, Lewis G, Peters TJ, Sharp D. Assessing mental health in primary care research using standardized scales: can it be carried out over the telephone? Psychol Med. 2004;34:157-162.

7. deLeeuw ED, Hox JJ. I am not selling anything: 29 experiments in telephone introductions. Int J Public Opin Res. 2004;16(4):464-473.
8. Boehm $\mathrm{H}$, Bonnel $\mathrm{W}$. The use of peer review in nursing education and clinical practice. J Nurses Staff Dev. 2010;26(3):108-115.

9. Winn W, Snyder D. Cognitive perspectives in psychology. In: Jonassen DH, editor. Handbook of Research for Educational Communications and Technology. New York: Macmillan; 1996: $112-142$.

10. McKinley RK, Williams V, Stephenson C. Improving the content of feedback. Clin Teach. 2010;7:161-166.

11. McCannel CA, Reed DC, Goldman DR. Ophthalmic surgery simulator training improves resident performance of capsulorhexis in the operating room. Ophthalmology. Epub June 21, 2013.

12. Sandelowski M. Whatever happened to qualitative description? Res Nurs Health. 2000;23(4):334-340.
Clinical Ophthalmology

\section{Publish your work in this journal}

Clinical Ophthalmology is an international, peer-reviewed journal covering all subspecialties within ophthalmology. Key topics include: Optometry; Visual science; Pharmacology and drug therapy in eye diseases; Basic Sciences; Primary and Secondary eye care; Patient Safety and Quality of Care Improvements. This journal is indexed on

Submit your manuscript here: http://www.dovepress.com/clinical-ophthalmology-journal

\section{Dovepress}

PubMed Central and CAS, and is the official journal of The Society of Clinical Ophthalmology (SCO). The manuscript management system is completely online and includes a very quick and fair peer-review system, which is all easy to use. Visit http://www.dovepress.com/ testimonials.php to read real quotes from published authors. 